\title{
Influence of High Asphaltene Feedstocks on Processing
}

\author{
M.M. Abu-Khader ${ }^{1}$ and J.G. Speight ${ }^{2}$ \\ 1 Department of Chemical Engineering, FET, Al-Balqa Applied University, Amman-Jordan \\ 2 CD \& W Inc., Laramie, Wyoming 82070, USA \\ e-mail: mak@accessme.com - jamessp8@aol.com
}

Résumé - Influence des charges élevées d'asphaltène sur le raffinage - Les composants de l'asphaltène sont, par définition, une fraction insoluble obtenue par précipitation depuis le pétrole, l'huile lourde ou le bitume et qui n'a par conséquent pas de structure simple, unique ou de poids moléculaire spécifique. Quand ils sont dispersés dans le pétrole, les composants de l'asphaltène en augmentent de manière importante la viscosité et affectent négativement la productivité des puits et/ou les moyens de raffinage. Du fait de changements dans la composition du pétrole ou de variations de température ou de pression, le pétrole (un système stable dynamique) peut être perturbé et les composants de l'asphaltène sont susceptibles de précipiter. Le but de cette analyse est d'étudier les méthodes au moyen desquelles le dépôt d'asphaltène peut être prévu ou déterminé et les méthodes au moyen desquelles il peut être atténué.

\footnotetext{
Abstract - Influence of High Asphaltene Feedstocks on Processing - Asphaltene constituents are, by definition, a solubility class that is precipitated from petroleum, heavy oil and bitumen and therefore do not have a single, unique structure or specific molecular weight. When dispersed in petroleum, asphaltene constituents appreciably increase petroleum viscosity and adversely affect the productivity of oil wells and/or the means of refining. Owing to the changes in the composition of petroleum as well as variations of temperature, pressure, petroleum (a dynamic stable system) may be disturbed and asphaltene constituents are likely to be precipitated. The purpose of this review is to examine the methods by which asphaltene deposition can be predicted or determined and hence methods by which deposition can be mitigated.
} 


\section{THE NATURE OF PETROLEUM ASPHALTENE CONSTITUENTS}

Petroleum is a complex mixture of hydrocarbons and heteroatom organic compounds of varying molecular weights and polarity (Speight, 2006 and references cited therein).

A common practice for the purpose of research is to separate petroleum into four fractions: saturates, aromatics, resins, and asphaltene constituents (Speight, 2006 and references cited therein; Liao and Geng, 2000; Sheu, 2002). The definition of the nonvolatile constituents of petroleum (i.e., the asphaltene constituents, the resin constituents, and, to some extent, part of the oils fraction insofar as nonvolatile oils occur in residua and other heavy feedstocks) is an operational aid. It is difficult to base such separations on chemical or structural features. This is particularly true for the asphaltene constituents and the resin constituents, for which the separation procedure not only dictates the yield but can also dictate the quality of the fraction (Speight, 2004a). Thus, some aspects of recovery and refining chemistry, especially the chemistry of the deposition of asphaltene material (degradation or reaction products of the asphaltene constituents and the resin constituents), can be proposed by virtue of the studies that have led to further knowledge of the nature of asphaltene constituents and the resin constituents and particularly the nature of their interaction in crude oil (Speight, 2004b).

Thus, asphaltene constituents are, by definition, a solubility class that is precipitated from petroleum, heavy oil and bitumen by the addition of an excess of a liquid paraffin hydrocarbon. In addition, the composition of the asphaltene fraction is dependent upon the nature of the hydrocarbon precipitant, the ratio of the volume of the precipitant to the volume of feedstock, to the contact time, and to the temperature at which the precipitation occurs (Speight, 2006 and references cited therein). Simply, asphaltene constituents are high molecular weight, aromatic, polar compounds containing carbon, hydrogen, oxygen, nitrogen, sulfur and some heavy metals such as vanadium and nickel. For this reason, the asphaltene constituents do not have a single, unique structure or specific molecular weight.

When dispersed in petroleum, asphaltene constituents appreciably increase petroleum viscosity and adversely affect the productivity of oil wells and/or the means of refining. Owing to the changes in the composition of petroleum as well as variations of temperature, pressure, petroleum (a dynamic stable system) may be disturbed and asphaltene constituents are likely to be precipitated (Speight, 1996; Speight and Long, 1996).

The purpose of this review is to examine the methods by which asphaltene deposition can be predicted or determined and hence methods by which deposition can be mitigated.

\section{ASPHALTENE CONSTITUENTS PROPERTIES}

A predictive approach based on computer assisted structure elucidation and atomistic simulations for the estimation of the thermodynamic properties of condensed phase systems has been presented (Diallo et al., 1994). The approach involved the use of molecular mechanics calculations and simulations to estimate the molar volume, density, cohesive energy, solubility parameter, enthalpy, thermal expansion coefficient and specific heat at constant pressure of the model asphaltene structures in volumetric and thermal properties from molecular dynamic simulations.

In addition, the electrokinetic charges on asphaltene constituents are dependent on the solution $\mathrm{pH}$, ionic strength, ionic composition and the degree of hardness of the electrolyte solution (Kokal et al., 1995). Asphaltene constituents are negatively charged in the neutral $\mathrm{pH}$ range. An increase in the ionic strength of the aqueous solution leads to a decrease in the electrophoretic mobility (and charge) of asphaltene constituents. This effect is consistent with the compression of the electric double layer by indifferent electrolytes. It is possible to measure the electrophoretic mobility of asphaltene constituents in non-aqueous solvents with relatively high permittivity, for example; nitromethane and nitrobenzene. Also, the adsorption of asphaltene constituents on mineral surfaces is influenced by the surface charge on asphaltene constituents as well as on the mineral. Adsorption of asphaltene constituents from toluene solutions on minerals exhibits Langmuir Type I adsorption isotherms which indicate mono-layer adsorption.

Based on surface tension, viscosity, dielectric relaxation, conductivity, and small angle neutron scattering measurements, asphaltene molecules exhibit a strong propensity for self-association and that these aggregates are approximately spherical in shape (Sheu et al., 1991). The conductivity and dielectric relaxation measurements suggest that the electron transformation between asphaltene molecules is the main mechanism in forming aggregates, but these aggregates do not percolate at either high concentration or high temperature $\left(60^{\circ} \mathrm{C}\right)$.

Fluorescence depolarization techniques have been used to measure asphaltene molecular size, and establish the substantial difference between asphaltene constituents derived petroleum (Buch et al., 2003). The method can be used to track the changes of the asphaltene constituents from a petroleum atmospheric residuum subjected to increasing thermal severity of catalytic hydrothermal cracking.

Following from the polarity concept (Speight and Long, 1996 and references cited therein), it has been reported (Goual and Firoozabadi, 2002) that the polarity of asphaltene constituents and resins affects precipitation strongly. For a given petroleum fluid, asphaltene constituents have a higher dipole moment than resin constituents. However, resin constituents from one petroleum fluid can have a 
higher dipole moment than asphaltene constituents from another petroleum.

While the polarity affects the solubility parameter (Speight, 1999), application of a theoretical model allows calculation of the theoretical distributions of the solubility parameter of resins and asphaltene constituents (Higuerey et al., 2001). This allows for an evaluation of the residuum quality of a thermal catalytic steam cracking process and also allows an explanation of the greater stability of such a residuum relative to visbreaking residua.

In addition, molecular weight (MW) distributions of the asphaltene aggregates formed when a solvent is injected into a crude oil have been investigated (Dabir et al., 1996). The effects of various factors such as the nature of the solvent, the solvent-to-oil volumetric ratio and ageing of the solution showed that if the asphalt- or asphaltene-containing solution has not been aged for long enough, a bimodal molecular weight distribution is obtained which is presumably due to the existence of two different types of aggregates with distinct structures and mechanisms of formation. However, after a sufficiently prolonged period the molecular weight distribution is unimodal.

\section{ASPHALTENE PRECIPITATION}

The separation of asphaltene constituents, reacted asphaltene constituents, or coke (heavy organic deposition) is a common problem in petroleum refining. This problem has increased due to the need to use heavy crude oil as refinery feedstocks for processes such as cracking distillation, thermal cracking, visbreaking, coking and catalytic cracking. While the majority of processes are designed to crack asphaltene constituents to liquid and coke, preheating feedstocks prior to injection into the reactor can well change the character of the reacted asphaltene product and delay the onset of coking.

In fact, any process that changes the solvency or dispersability of asphaltene constituents in petroleum can induce asphaltene separation. This is clearly evident when changing the operating pressure which can change the crude oil density sufficiently enough to cause asphaltene constituents to flocculate and separate from the feedstock. This is due to changing from an oversaturated condition to below the bubble point of the feedstock.

There are methods by which the stability of asphaltene constituents in petroleum varying API gravity can be predicted using the Oliensis spot test, the colloidal instability index, the asphaltene-resin ratio, and solvent titration method using near infrared detection (Asomaning, 2003). The experimental stability data via correlation were validated with field deposition data, and discussed the effectiveness of the various tests as predictors of the stability of asphaltene constituents in oils. The Colloidal Instability Index and the solvent titration method were found useful to predict propensity of crude oil towards asphaltene precipitation is better than both the Asphaltene-Resin ratio and the Oliensis Spot Test. Also, the author proposed the use of live oil depressurization as the test for predicting the stability of asphaltene constituents for oils with low asphaltene content where most stability tests fail.

Refractive index can also be used to enhance our understanding of the behavior of asphaltene constituents in petroleum (Wattana et al., 2003). However, as asphaltene constituents began to separate from petroleum, the refractive index can no longer follow the linear mixing rule. However, the refractive index of the asphaltene fraction can be predicted from the refractive index of petroleum crude oils and there is the possibility of predicting the properties and characteristics of the asphaltene constituents by measuring the refractive index of the petroleum.

More in keeping with processing options, the effect of diluent composition on asphaltene precipitation using the hot filtration method and there is also the concept of using deasphalted oil or resin constituents to inhibit asphaltene separation when n-heptane is added (Al-Sahhaf et al., 2002).

Synthetic dispersants can greatly increase the dispersability of asphaltene constituents in crude oils at low concentrations.

Thus, a decrease in $n$-heptane insoluble material is observed in the presence of dodecylbenzenesulfonic acid indicating an increase in the colloidal stability of the asphaltene constituents (Pillon, 2001). Poly(maleic anhydride-1octadecene) polymer is an effective flocculant, and that the flocculation of $n$-heptane insoluble material varied depending on the weight ratios of the polymer to the asphaltene constituents. The presence of an anhydride and unsaturation makes the maleic anhydride too reactive leading to chemical changes and the precipitation of asphaltene constituents and other aromatic molecules found in fuel oils (Pillon, 2001).

Furthermore, surface properties of asphaltene constituents precipitated from crude oil with different volumes of n-heptane (Parra-Barraza et al., 2003) indicate that the amount of $\mathrm{n}$-heptane determines the electrokinetic behavior of asphaltene constituents in aqueous suspensions. Both sodium dodecyl sulfate (an anionic surfactant) and cetylpyridinium chloride (a cationic surfactant) adsorb specifically onto asphaltene constituents and reverse the sign of the zeta potential under certain conditions. Also, these surfactants may be potential candidates to aid in controlling the stability of crude oil dispersions.

Following from this, synthetic dispersants are claimed to require one or more groups that complex with the polynuclear aromatic structures in asphaltene constituents and long paraffin tails that promote dispersability in the rest of the oil (Wiehe and Jermansen, 2003). By synthesizing families of prospective dispersants, one sulfonic acid group was determined to be the most effective head attached to a two ring aromatic structure. A straight chain 
paraffin tail is not effective above 16 carbons because of decreased solubility in the petroleum caused by crystallization with other tails and with waxes in the oil. In addition, n-alkyl-aromatic sulfonic acids lose their ability to disperse asphaltene constituents with time. Both of these problems were claimed to be negated by using two branched tails of varying length proportions between the two tails. As a result, the effectiveness of the dispersant increases with total tail length, well above 30 carbons and it remains effective with time.

\section{MODELS FOR ASPHALTENE PRECIPITATION}

Among the first theoretical models of asphaltene precipitation are the solubility models and its modifications (Mannistu, 1997) which were derived from the FloryHuggins solution theory, and have preliminarily described the precipitation of asphaltene constituents. But both models fail to pay attention to the interactions of asphalteneasphaltene, asphaltene-resin, and any other interactions of asphaltene constituents with other constituents in petroleum. It has been manifested that these interactions are very important (Speight and Long, 1996; Mansoori, 1997).

Considering the importance of the asphaltene deposition modeling, and the limitations of many models, it is necessary to approach this subject in a more realistic and accurate manner. For example, the steric colloidal model is based on the assumption that the asphaltene constituents, exist in oil as suspended particles and particle suspension is assumed to be caused by resins (Leontaritis and Mansoori, 1992).

In another model, asphaltene molecules were assumed to be flat hard discs (unit sheets) that can stack to any arbitrary degree in the solvent (Brandt et al., 1995). They express the volume fraction of asphaltene 'stacks' as a function of asphaltene concentration, asphaltene cohesive/stacking energy, asphaltene-solvent interaction energy, and asphaltene unit sheet/stack excluded volume.

Fractal aggregation describes asphaltene deposition in a more realistic manner. This model is based on the fact that resins play a key role in asphaltene deposition (Park and Mansoori, 1988; Janardhan and Mansoori, 1993) and describes the size distribution of an aggregating polydisperse system.

In the fractal aggregation model, it is assumed that pi-pi interactions are the principal means by which asphaltene constituents associate. This assumption may not be completely valid because of the evidence that favors hydrogen bonding between the molecular species and the observation that asphaltene-resin interactions may predominate over asphaltene-asphaltene interactions in petroleum. The concept that asphaltene-asphaltene interactions may be the predominant interactions is true for solutions of asphaltene constituents, and this is reflected in the molecular weight data (Speight et al., 1985) but there is no guarantee that these interactions are predominant in petroleum especially with evidence that indicates the high potential for other interactions. (Moschopedis and Speight, 1976; Speight, 1994).

A number of different models that have been applied to modeling of asphaltene precipitation and estimating asphaltene solubility in various systems has been critically reviewed (Andersen and Speight, 1999). Particular attention was paid to the basic assumptions and the performance of the models as compared to the present knowledge of composition and phase equilibrium of asphaltene constituents. The molecular weight of the asphaltene was the main parameter in all models and only a few models take the aggregating nature of the asphaltene constituents into account, and the inclusion of the solubility parameter means that extensive modification to the model is needed. It was concluded that the present models employed for predictability of asphaltene constituents precipitation are lacking in several respects and are not quantitatively accurate.

\section{EFFECTS OF ASPHALTENE CONSTITUENTS DURING REFINING}

The effect of asphaltene constituents during refining is often manifested as premature coke formation during heavy oil processing or during residuum processing.

Heavy oil is a type of petroleum that cannot be recovered through a well by conventional means and requires thermal or chemical stimulation for recovery. Residua are the non-volatile fractions of petroleum that remain after atmospheric or vacuum distillation.

Heavy oils and residua contain higher proportions of asphaltene constituents and resin constituents that, because of the content of polynuclear aromatic compounds, provide hurdles to conversion. The high thermal stability of polynuclear aromatic systems prevents thermal decomposition to lower boiling point products and usually results in the production of substantial yields of thermal coke. Furthermore, the high concentrations of heteroatom compounds (nitrogen, oxygen, sulfur) and metals (vanadium and nickel) in heavy oils and residua have an adverse effect on catalysts. Therefore, process choice of ten favors thermal process but catalytic processes can be used as long as catalyst replacement and catalyst regeneration is practiced.

However, on the positive side, a substantial fraction of the heavy oil constituents and the residuum constituents are converted to liquid products that vary from naphtha to vacuum gas oil. However, process conditions must be chosen carefully or the major products will be coke and gas, the formation of which is thermodynamically favored. 
Most conversion processes for high-asphaltene feedstocks can be a combination of:

- separation,

- thermal conversion,

- catalytic cracking,

- hydrocracking, or

- hydrotreating (Moschopedis et al., 1998; Speight and Ozum, 2002).

\subsection{Separation}

Distillation is the most common separation choice, but it is the process by which residua are produced and then the need to process the residua remains. However, the use of solvent deasphalting is increasing; liquid propane or liquid butane and mixtures thereof are used as the solvent under pressure sufficient to maintain the hydrocarbon in the liquid phase.

In the deasphalting process, lower molecular weigh soluble constituents are separated from the higher molecular weight insoluble constituents. The quality of the soluble deasphalted oil is dependent upon the nature of the feedstock and, whatever the outcome, the need remains for use or disposal of the insoluble product. Usually, the insoluble product is sent to the asphalt plat for immediate use as asphalt or to be blended with other similar product to produce asphalt.

\subsection{Visbreaking}

Visbreaking is a low conversion thermal process that is designed to reduce the viscosity of the feedstock so that the product meets the specifications required for fuel oil. The process products are transportation boiling range liquids ( $<30 \% \mathrm{v} / \mathrm{v}$ yield) and a high-boiling product that meets fuel oil specifications (Speight and Ozum, 2002). The process cannot tolerate coke formation and it is coking that limits feedstock conversion, rather than fuel oil specifications.

A visbreaker reactor may use a soaker drum or a coil reactor. The thermally reactive asphaltene constituents of the feedstock must be monitored carefully otherwise coke formation is rampant. For this reason, residence time of the feedstock into the thermal zone must be controlled. To do this, the soaker drum is much smaller in volume than the furnace tube to limit the residence time with the entire liquid product flowing overhead. Alternatively, the entire visbreaker may be a long tube coiled within a furnace.

In spite of necessary cautions, asphaltene constituents can cause coke formation, when accumulate on the rector (soaker or coil) walls. Period decoking is needed.

\subsection{Coking}

Coking processes are the most common conversion processes for feedstocks that have high asphaltene content (Moschopedis et al., 1998; Speight and Ozum, 2002). The coke is a low value product that retains most of the heteroatoms and metals (catalyst poisons) and the deposition of the catalyst poisons into the coke is accompanied by a liquid overhead product that is relatively high in hydrogen. The overhead product, depending upon the boiling range, may be suitable for catalytic upgrading and/or hydrotreating.

The thermal reaction is believed to be first-order (Olmstead and Freund, 1998) although there is the potential that it is, in fact, a multi-order reaction process, but because of the multiplicity of the reactions that occur, it appears as a pseudo first-order process. However, it is definite that there is an induction period before coke begins to form that is triggered by phase separation of reacted asphaltene product (Magaril et al., 1971 and references cited therein; Speight, 1987; Wiehe, 1993 and references cited therein; Speight 2003 and references cited therein).

\subsubsection{Delayed Coking}

In the delayed coking process, the feedstock is heated to high temperatures $\left(480\right.$ to $500^{\circ} \mathrm{C}$ ) in a furnace and then reaction is allowed to continue in a cylindrical, insulated drum. The volatile products pass overhead into a fractionator and coke accumulates in the drum. Any high-boiling liquid product from the fractionator is recycled to the coker furnace. When the drum is full with coke, the reacting feedstock is directed to a second drum. The coke is removed from the first drum by hydraulic drilling and cutting after which the drum is ready for the next 16-24 hour reaction cycle.

During this process, the asphaltene and resin constituents in the feedstock are converted to coke in accordance with their respective carbon residue values (ca. 50\% w/w for asphaltene constituents and ca. $35 \% \mathrm{w} / \mathrm{w}$ for resin constituents).

\subsubsection{Fluid Coking and Flexicoking}

In the fluid coking process, the feedstock is sprayed on a hot, fluidized bed of coke particles in the reactor. The volatile products go overhead to a fractionator while the coke particles are removed out of the bottom and transferred to another reactor where the coke is partially burned with air to provide the heat for the process. This coke is then recirculated back to the reactor. The fluid coking process produces much more coke than is required for heat, therefore excess coke is withdrawn at the bottom of the reactor. Any high-boiling liquid product is recycled to the reactor from the fractionator. This is used to scrub coke fines from the reactor vapors and to improve the quality of the liquid product.

In the flexicoking process, a third vessel (the gasifier) is installed after the fluid coker. In the gasifier, coke is gasified with steam and air under net reducing conditions to produce a low energy gas containing hydrogen, carbon monoxide, nitrogen, and hydrogen sulfide. After removal of 
the hydrogen sulfide, the gas is burned as a clean fuel within the refinery and/or in a nearby power plant. Only a small amount of coke (about 3\%) needs to be withdrawn to prevent vanadium and nickel from accumulating in the gasifier.

As with delayed coking, asphaltene and resin constituents in the feedstock are converted to coke in accordance with their respective carbon residue values (ca. 50\% $\mathrm{w} / \mathrm{w}$ for asphaltene constituents and ca. $35 \% \mathrm{w} / \mathrm{w}$ for resin constituents).

Although the liquid yield from fluid coking may be one or more percentage point higher than for delayed coking, it is the higher boiling gas oil constituents (the relatively low coke producers, i.e., carbon reside $<10 \% \mathrm{w} / \mathrm{w} /$ ) that allow higher conversion to overhead product in the fluid coker. The fluid bed operation has very little effect on the asphaltene and resin constituents. The conversion of these materials to coke is effected by rapid and irreversible reactions that occur immediately upon the application of heat.

\subsection{Cracking}

\subsubsection{Catalytic Cracking}

Catalytic cracking of heavy oils and residua has a much better selectivity to desired products (high gasoline and low gas yields) than coking.

In the fluid catalytic cracking process, the feedstock is sprayed on a zeolite catalyst in a short contact time, riser reactor. The vaporized product flows to a fractionator while the catalyst with coke and adsorbed hydrocarbons flow to a fluidized bed regenerator where the coke and hydrocarbons are burned off the catalyst.

However, the process requires much higher quality feeds than coking and the expensive zeolite catalysts are intolerant to sodium, nickel, vanadium, and nitrogen as well as to limitations on the amount of coke that can be burned in the regeneration step. As a result, the feedstock must be chosen carefully. Thus atmospheric residua are preferable rather than vacuum residua, while mixtures of vacuum gas oil and atmospheric residua are even more preferred.

Again, the presence of asphaltene and resin constituents is the determining factor through the deposition of nitrogen species, metal constituents, and coke on the catalyst. It is the rapid and irreversible reactions that occur immediately upon the application of heat are, ultimately detrimental to the catalyst.

\subsubsection{Hydrocracking and Hydrotreating}

Hydrocracking is similar to catalytic cracking, with hydrogenation superimposed and with the reactions taking place either simultaneously or sequentially. Hydrocracking is also applicable to high-asphaltene feedstocks but catalyst costs and hydrogen costs can be high.

In the hydrocracking process, the feedstock and hydrogen are passed over a catalyst to produce the products. It is presumed that the addition of hydrogen increases the coke induction period by hydrogenating polynuclear aromatic systems thereby reducing the frequency of aromatic constituents from combining to form larger polynuclear aromatic systems. This is possible but, in some cases, unlikely.

Investigation of hydrocracking products and hydrocracking chemistry indicates that the rapid and irreversible reactions of the asphaltene and resin constituents that occur during coking are slighty affected by the hydrogen and the catalyst. There are indications that the chemistry of the conversion of the asphaltene constituents and resin constituents in a hydrocracker mirrors the thermal conversion and it is the presence of hydrogen that prevents borderline

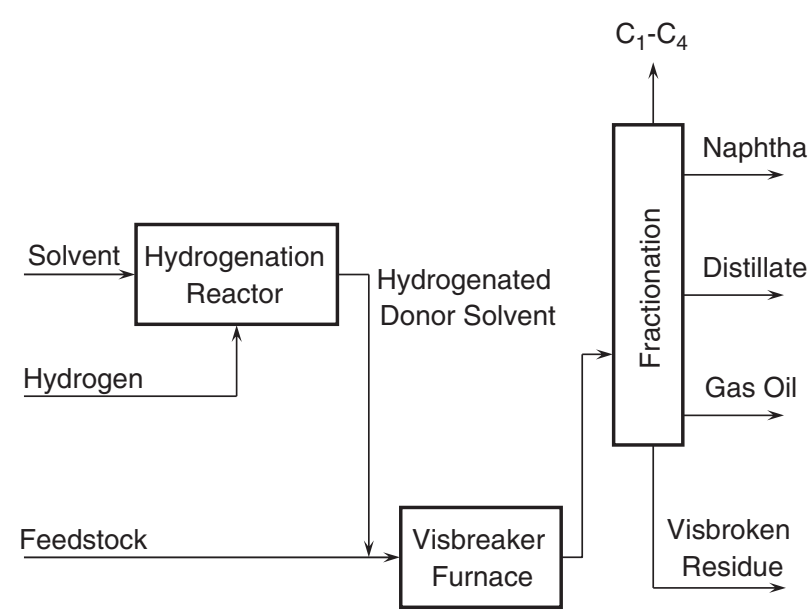

Figure 1

The hydrovisbreaking option for heavy feedstocks conversion.

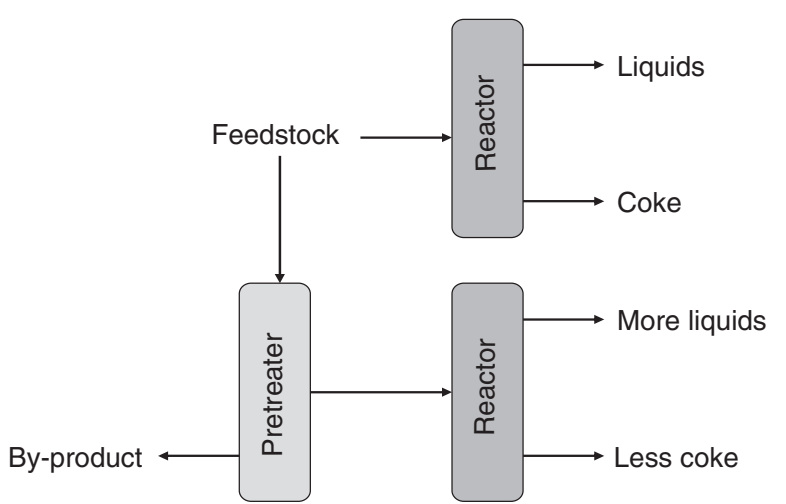

Figure 2

Pretreatment options for heavy feedstocks conversion. 
coke formers from producing coke, thereby allowing higher yields through hydrocracking.

On the other hand, hydrotreating, which is performed at a lower temperature than the hydrocracking, lends itself to hydrogenation of the asphaltene and resin constituents. Therefore pre-treatment of heavy feedstock leading to hydrogen of acceptable sites offers an option to control the process chemistry.

\section{THE FUTURE OF ASPHALTENE CONSTITUENTS IN THE REFINERY}

Asphaltene constituents and, to a lesser extent, resin constituents can cause major problems in refineries through unanticipated coke formation and/or through excessive coke formation. Recognition of this is a step in the direction of mitigating the problem.

Improvement in heavy feedstocks conversion may be sought in the use of specific chemical additives. However, to improve the conversion of heavy feedstocks it is necessary to understand the chemistry of conversion. Well-intentioned though some of the efforts have been to date, failure to understand the chemistry and attempting to classify heavy feedstock conversion under general rules is not the answer. As a result, there is a need for great effort to improve heavy feedstock conversion processes.

A key step is to recognize that hydrogen management plays a major role. Only if the additive assists in hydrogen management then it will have a chance of success. Therefore, future growth in heavy feedstocks conversion is to improve visbreaking and conversion processes in general by reducing coke formation and by inhibiting the rapid irreversible reaction of the asphaltene and resin constituents. In addition, it is essential to take advantage of the natural constituents of the feedstock to generate in situ hydroprocesses by increasing the amount of available hydrogen to effectively reduce the raid irreversible reactions that cause the commencement of coke formation.

Thus, in future, refineries will use hydrogen as a pretreatment step in refining in which the feedstocks are first hydrotreated before conversion. There is adequate evidence that this will be successful whether it is in pretreatment for visbreaker feedstocks (Fig. 1) or for fluid catalytic cracking feedstocks (Fig. 2).

Cost will, as always, be the key. But, with the need for more liquid fuels and the ability of hydrogen use to cut catalyst costs and to mitigate potential environmental problems, the way is open. For example, a recent hydrovisbreaking innovation (Marzin et al., 1998) uses a dual catalyst system to achieve higher conversion levels and more stabilized residue than conventional visbreaking technology.

\section{REFERENCES}

Al-Sahhaf, T.A., Fahim, M.A. and Elkilani, A.S. (2002) Retardation of asphaltene precipitation by addition of toluene, resins, deasphalted oil and surfactants. Fluid Phase Equilibr., 194-197, 10451057.

Andersen, S.I and Speight, J.G. (1999) Thermodynamic models for asphaltene solubility and precipitation. J. Petrol.Sci.Eng., 22, 53-66.

Asomaning, S. (2003) Test Methods for Determining Asphaltene Stability in Crude Oils. Petrol.Sci. Technol., 21, 581.

Brandt, H.C.A., Hendriks, E.M., Michels, M.A.J. and Visser, F. (1995) Thermodynamic modeling of asphaltene stacking. J. Phys. Chem., 99, 10430.

Buch, L., Groenzin, H., Buenrostro-Gonzalez, E., Andersen, S.I., Lira-Galeana, C. and Mullins, O.C. (2003) Molecular size of asphaltene fractions obtained from residuum hydrotreatment. Fuel, 82, 1075-1084.

Dabir, B., Nematy, M., Mehrabi, A.R., Rassamdana, H. and Sahimi, M. (1996) Asphalt flocculation and deposition: III. Molecular weight distribution. Fuel, 75, 1633-1645.

Diallo, M.S., Cagin, T., Faulon, J.L. and Goddard, III W.A. (1994) Thermodynamic Properties of Asphaltene Constituents: A Predictive Approach Based on Computer Assisted Structure Elucidation and Atomistic Simulations, in Asphaltene Constituents and Asphalts, Developments in Petroleum Science, Yen, T.F. and Chilingarian, G.V. (eds.), Elsevier, Amsterdam, The Netherlands, Chap. 5.

Goual, L. and Firoozabadi, A. (2002) Measuring Asphaltene constituents and Resins, and Dipole Moment in Petroleum Fluids. AIChE J., 48, 2646-2663.

Higuerey, I., Rogel, E. and Pereira, P. (2001) Residue Stability Study in a Thermal Catalytic Steam Cracking Process Through Theoretical Estimation of the Solubility Parameter. Petrol. Sci. Technol., 19, 387.

Hong, E. and Watkinson, P. (2004) A study of asphaltene solubility and precipitation. Fuel, 83, 1881-1887.

Janardhan, A.S. and Mansoori, G.A. (1993) Fractal nature of asphaltene aggregation. J. Petrol. Sci. Eng., 9, 17-27.

Kokal, S.L., Najman, J., Sayegh, S.G. and George, A.E. (1992) J. Can. Petrol. Technol., 31, 24.

Kokal, S., Tang, T., Schramm, L. and Sayegh, S. (1995) Electrokinetic and adsorption properties of asphaltene constituents. Colloid. Surface A, 94, 253-265.

Liao, Z. and Geng, A. (2000) Asphaltene constituents in oil reservoir recovery. Chinese Sci. Bull., 45, 8.

Leontaritis, K.J. and Mansoori, G.A. (1992) A colloidal model for asphaltene flocculation from petroleum fluids. Iran. J. Sci. Technol., 16, 2-3, 249-267.

Magaril, R.Z., Ramazeava, L.F. and Aksenova, E.I. (1971) Kinetics of Coke Formation in the Thermal Processing of Crude Oil. Int. Chem. Eng., 11, 250 .

Mannistu, K.D., Yarranton, H.W. and Masliyah, J.H. (1997) Solubility modeling of asphaltene constituents in organic solvents. Energ. Fuel, 11, 615.

Mansoori, G.A. (1997) Modeling of asphaltene and other heavy organic deposition. J. Petrol.Sci. Eng., 17, 101.

Marzin, R., Pereira, P., McGrath, M.J. and Feintuch, H.M. (1998) New residue process increases conversion, produces stable residue in Curacao refinery. Oil Gas J., 96, 44, 79.

Moschopedis, S.E. and Speight, J.G. (1976) Fuel, 55, 187. 
Moschopedis, S.E., Ozum, B. and Speight, J.G. (1998) Upgrading Heavy Oils, Rev. Process Chem. Eng., 1, 201.

Olmstead, W.N. and Freund, H. (1998) Proceedings, AIChE Spring National Meeting, New Orleans, Louisiana.

Park, S.J. and Mansoori, G.A. (1988) Aggregation and deposition of heavy organics in petroleum. Int. J. Energ. Sources, 10, 109-125.

Parra-Barraza, H., Hernández-Montiel, D., Lizardi, J., Hernández, J., Urbina, R.H. and Valdez, M.A. (2003) The zeta potential and surface properties of asphaltene constituents obtained with different crude oil/n-heptane proportions. Fuel, 82, 869-874.

Pillon, L.Z. (2001) Effect of Dispersants and Flocculants on the Colloidal Stability of Asphaltene Constituents. Petrol. Sci. Technol., 19, 863 .

Sheu, E.Y. (2002) Petroleum asphaltene-properties, characterization, and issues. Energ. Fuel, 16, 74-82.

Sheu, E.Y., Storm, D.A. and De Tar, M.M. (1991) Asphaltene constituents in polar solvents. J. Non-Cryst. Solids, 131-133, 1, 341-347.

Speight, J.G. (1987) Initial reactions in the coking of residua. Preprints, Am. Chem. Soc. Div. Petrol. Chem., 32, 2, 413.

Speight, J.G. (1994) Asphaltene Constituents and Asphalts. Developments in Petroleum Science, Yen, T.F. and Chilingarian, G.V. (eds.), Elsevier, Amsterdam, The Netherlands, Vol. 40, Chap. 2.

Speight, J.G. (1996) Asphaltene constituents in crude oil and bitumen: structure and dispersion, Advances in Chemistry Series. Am. Chem. Soc. Washington, DC, p. 251.

Speight, J.G. (1999) The chemical and physical structure of petroleum: effects on recovery operations. J. Petrol. Sci. Eng., 22, $1-3,3-15$.

Speight, J.G. (2003) Thermal Cracking of Petroleum, in Natural and Laboratory-Simulated Thermal Geochemical Processes, Ikan,
R. (éd.), Kluwer Academic Publishers Inc., Dordrecht, The Netherlands, Chap. 2.

Speight, J.G. (2004a) Petroleum asphaltene constituents - Part 1 Asphaltene constituents, resins and the structure of petroleum. Oil Gas Sci.Technol., 59, 5, 467-477.

Speight, J.G. (2004b) Petroleum asphaltene constituents - Part 2 The effect of asphaltene constituents and resin constituents on recovery and refining processes. Oil Gas Sci. Technol., 59, 5, 479-488.

Speight, J.G. (2006) The Chemistry and Technology of Petroleum, 4th ed., CRC Press, Taylor and Francis Group, Boca Raton, Florida.

Speight, J.G. and Long, R.B. (1996) The concept of asphaltene constituents revisite., Fuel Sci.Technol. Int., 14, 1 .

Speight, J.G. and Ozum, B. (2002) Petroleum Refining Processes, Marcel Dekker Inc., New York.

Speight, J.G., Wernick, D.L., Gould, K.A., Overfield, R.E., Rao, B.M.L. and Savage, D.W. (1985) Revue de l'Institut français $d u$ pétrole, $\mathbf{4 0}, 51$.

Wattana, P., Wojciechowski, D.J., Bolaños, G. and Fogler, H.S. (2003) Study of Asphaltene Precipitation Using Refractive Index Measurement. Petrol.Sci. Technol., 21, 591.

Wiehe, I.A. (1993) A Phase-Separation Kinetic Model for Coke Formation. Ind.Eng. Chem. Res., 32, 2447-2554.

Wiehe, I.A. and Jermansen, T.G. (2003) Design of Synthetic Dispersants for Asphaltene constituents. Petrol. Sci.Technol., 21, 527.

Final manuscript received in November 2006 